\title{
SURVEILLANCE OF TRYPANOSOMA SPP OF RODENTS AND STUDIES IN THEIR TRANSMISSION PROBABILITY BY FLEAS IN SOME RURAL EGYPTIAN AREAS
}

\author{
By \\ SALWA M. A. DAHESH ${ }^{1}$ AND MICHEAL W. MIKHAIL ${ }^{2}$, \\ Faculty of Medical Technology, AI Gabal Al Gharby University, Libya ${ }^{(1)}$ \\ Research Institute of Medical Entomology, The General Organization for Institutes \\ and Teaching Hospitals, Ministry of Health, Dokki, Egypt ${ }^{(1,2)}$ \\ Salwamohamed970@gmail.com
}

\begin{abstract}
A new public health problem arises from animal trypanosomes that afflict human by a disease called atypical human trypanosomiasis. Although humans have an innate protection against most Trypanosoma species, nineteen cases of atypical human trypanosomiasis caused by the animal trypanosome as T. b. brucei, $T$. vivax, T. congolense, $T$. evansi and T. lewisi have been recorded. Some of theserecorded cases were transient, six required trypanocidal treatments however two patients died. Rodent trypanosome, T.lewisi is transmitted via ingestion of fleas or their feces containing the infective stage, the metacyclic trypomastigote. Because of the high densities of various species of rodents and their distribution all over the country especially in rural areas, the present work aimed to evaluate the trypanosomiasis among rodents collected from November to March 2016 and study transmission probability by their fleas in some rural areas in Abu Alnomros Center, Giza. The overall trypanosomiasis prevalence among the different rodent species was (21 rats) $24.7 \%$. All the infected rats belonged to Rattus r. spp where the prevalence of infection with Trypanosoma lewisi among that species was very high $51.2 \%$ while none of rats belonged to Rattus norvegicus were infected. That may be attributed to the solid immunity gained by the $R$. norvegicus where most of the collected norvegicus were aged and weighed more than 200 grams. There was an inverse significant correlation between the densities of parasites and the weights of the hosts. The rat which recorded the highest parasite density (60,000 parasites/ microliter) was a female Rattus $r$. captured indoor (inside house). As to sex of Rattus rattus spp no significant difference was found between males and females in trypanosomiasis. Also there was no significant correlation between the densities of parasites and the number of white blood cells among Rattus rattus spp. All positive rats were collected indoors (from houses) and all the rats which were captured from outdoors (farms) were negative for $T$. lewisi. The difference between infections with trypanosomiasis among rats inhabited the houses and that found in farms was highly significant.

Only two species of fleas were found on rats, Xenopsylla cheopis and Leptopsylla segnis. The oriental fleas, $X$. cheopis, were found mainly on $R$. norvegicus where $57.5 \%$ of $R$. norvegicus were positive for $X$. cheopis while only one rat was positive for $L$. segnis. On other hand the rat fleas, L.segnis, were found mainly on Rattus rattus spp where $39 \%$ of these rats were positive for $L$. segnis. The present work revealed a significant correlation between the infection with $T$. lewisi and the presence of $L$. segnis on the rats however that correlation regarding $X$. cheopis was not significant.
\end{abstract}

\section{Introduction}

Trypanosomes are protozoan parasites widely distributed, infecting humans, wild and domestic animals. The typical pathogenic human trypanosomes cause sleeping sickness disease, or human African trypanoso- miasis (Hoare, 1972), and the Latin American Chagas disease (Rassi et al, 2010). Human African trypanosomiasis is a fatal disease found in sub-Saharan Africa and transmitted by tsetse flies. The disease is caused by two subspecies of trypanosomes; $T$. brucei gambiense which is responsible for the chronic form or Trypanosoma $b$. 
rhodesiense that causes the acute form. Chagas disease is caused by Trypanosoma cruzi, and transmitted mainly by triatomine bugs (Maraghi, 1995). The disease is endemic in Latin America where most cases are chronic and asymptomatic (Rassi et al, 2010).

On other hand, most of trypanosomes were thought to be infective only to animals, such as $T$. congolense, Trypanosoma $b$. brucei, and $T$. vivax, that are responsible for "nagana" or the complex animal trypanosomiasis in Africa. T. evansi is the causative agent of a disease called "surra" that is widely distributed among wild and domestic animals. Surra is found in Asia, Africa, Europe, and even South America (Gutierrez, 2010).

Man has an innate protection against most Trypanosoma sp. (Vanhamme 2003). However, nineteen cases of atypical human trypanosomiasis caused by $T$. b. brucei, $T$. vivax (Hoare, 1972), T. congolense (Truc et al, 1998), T. evansi (Joshi et al, 2005) and $T$. lewisi (Doke et al, 2011; Verma et al, 2011), which were previously non-infective to humans, have been reported. In recent years, $T$. lewis and T. evansi have emerged as potential pathogens for humans. Most of the recorded cases were transient, six cases required trypanocidal treatments while two of them died (Doke et al, 2011). Among fifteen humans cases reported in the period between 1974 and 2010, nine of them have been recorded since 2003. Some cases were identified by microscopic observation of trypanosomes while others by using molecular tools (Truc et al, 2013). Haridy et al. (2011) in Egypt reported camels naturally infected with $T$. evansi and the first Egyptian human case of zoonotic trypanosomiasis evansi.

In a trial for detecting the possible source of infection with atypical trypanosomiasis in a sick Thai infant, blood samples of 276 rodents were analyzed for identifying ITS1 sequence of trypanosomes. The result revealed that there was $96.4 \%$ similarity between ITS1 sequence of trypanosome obtained from $R$. tanezumi and that from the blood of the $T$. lewisi-infected Thai infant
(Sarataphan et al, 2007; Desquesnes et al, 2011). T. lewisi possess two antigenic variants the first one represents the initial reproducing population while the second represent the non-reproducing population. The reproduction rate is inhabited by ablastin (WHO, 1970) while the late population is cleared by antibody dependent cytotoxicity. During Infection of rat with $T$. lewisi the parasitaemia naturally resolves within 30 days providing solid immunity against reinfection (Maia da Silva, 2010). Inability of $T$. lewisi to infect a wide range of mammalian species may be due to the activation of complement through the alternative pathway, agglutinins and opsonins where the parasites infecting non-natural hosts are cleared in a very short time compared to their natural hosts (Jarvinen et al, 1976; Desquesnes et al, 2011).

The rodent species found in Egypt Governorates were Norway rat, Rattus norvegicus, white-bellied rat, $R$. rattus frugivorous, the grey-bellied rat, $R$. $r$. alexandrinus, house mouse, Mus musculus and finally the spiny mouse Acomys cahirinus. The flea species attacking rodents were the common species or the rat flea, Xenopsylla cheopis then the mouse flea, Leptopsylla segnis. Also other fleas as dog flea, Ctenocephalides canis and the sticktight flea Echidnophaga gallinacean were recorded. Highest flea indices were detected in Ismailia and Matrouh Governorates but El-Fayoum and North Sinai Governorates recorded the lowest ones. $R$. norvegicus was the highest manifested species with fleas because they live in places easy to dig barrows and also are suitable condition for fleas breeding. The lowest manifestation by fleas was recorded on Mus musculus and Acomys cahirinus. X. cheopis was the species of the highest frequent distribution on all domestic rodent species however the stick-tight flea, Echidnophaga gallinacea was the species which recorded the lowest distribution where they found only in Dakahlia and Ismailia (Mikhail et al, 2011). 
The present work aimed to evaluate the trypanosomiasis among rodents collected from November to March 2016 and to study transmission probability by their fleas in some rural areas in Abu Alnomros Center, Giza Governorate.

\section{Subjects, Material and Methods}

Well baited wire box traps were distributed at sunset in some selected residential rural houses in Abu Al-nomros Center, Giza Governorate. Distributed traps were collected next morning, enclosed with separate white bags and transported to laboratory.

Capturing and transporting of rodent animals throughout the present investigation were done (Rifaat et al, 1969). The collected animals (85 rats) were identified then anaesthetized with diethyl ether. Fleas on each animal were collected in white sheet by using a stiff hard brush (WHO, 1970). Fleas were preserved in $70 \%$ ethanol in separate labeled tube. Classification and Identification of fleas were done according to the key given by Hoogstraal (1956).

Blood samples were taken from hearts of the anaesthetized rats. Thin and thick blood films were prepared and stained with Giemsa stain to demonstrate the Trypanosoma spp. (Gracia, 2001).

The collected data were tabulated and statistically analyzed by PC using the Epi Info and SPSS for windows software packages. The 0.05 cut-off value was used as a criterion for statistical significance and all statistical tests were interpreted in a two-tailed fashion (Lehmann, 1975, Altman, 1992).

\section{Results}

The results were shown in tables (1 to 11), figures (1 to 10), and photos (1 to 6).

\section{Discussion}

In the present study the overall trypanosomiasis prevalence among the different rodent species was (21 rats) $24.7 \%$. All the infected rats belonged to Rattus rattus spp where the prevalence of infection with Trypanosoma lewisi among that species was very high $51.2 \%$. Regardless the rodent species the overall prevalence in the present study is close to that $(21.7 \%)$ recorded in Belo Horizonte, State of Minas Gerais, Brazil (Linardi et al, 2002) also in Venezuela which recorded $21.3 \%$ (Herrera et al, 1997) and in Italy 20\% (De Carnieri et al, 1964). The highest recorded prevalence was found in India 82.3\% (Laha et al, 1997). Other prevalences of rodent trypanosomiasis in different areas all over the world were $8.9 \%$ in Nigeria (Ugbomoiko, 1997), 13.2\% in both in Egypt (Abdel-Aal et al, 1997) and the USA (Eyles, 1952).

Regarding rodent species the prevalence of trypanosomiasis among Rattus rattus spp was $51.2 \%$ while no positive Norway rats (Rattus norvegicus) were recorded in the present work. That may be due to most of the collected Rattus norvegicus $95.4 \%$ recorded weights equal or more than 100 grams and $86.4 \%$ weighed 200 grams or more. The high weights of the collected Norway rats reflect their ages and their corresponding immunity against trypanosomiasis.

The multiplication of $T$. lewisi in rodents is well known (Albright et al, 1991). After a period of rapid multiplication of trypanosomes (10 days), they stop growing and their numbers stabilize for several weeks, then the parasites disappear suddenly from the blood so the rat develops a solid immunity against Trypanosoma lewisi reinfection. On other hand a trick made by $T$. lewisi minimizes the effects of the host immune response known as mimicry. Firstly the parasites coat their surfaces with a host protein layer, ablastin, identified as IgE that forbids the trypanosomes from dividing or multiplying. After several weeks, IgM antibodies are produced by the host and recognize this complex on the parasite's surface and then the complement system is activated resulting in rapid lysis of the parasites in the blood. So, the blood smears of adult rats show low densities or fewer trypanosomes than those of younger or immature animals. Since Norway rats attain sexual maturity at 75 days and only $5 \%$ of the population survives 12 months (Davis, 1948), the rats most likely to 
be infected before or during their first mating. So, it is recommended to use hemoculture rather than stained blood films to show infections in many rats, mainly adults that would be considered negative by blood films (Linardi et al, 2002). Although no trypanosomiasis was found among $R$. norvegicus in the present study, Chaisiri (2015) mentioned that the rats belonged to that species were identified as reservoirs for most of zoonotic helminthes.

Regarding the sex of $R$. rattus spp no statistically significant difference was found between males and females in trypanosomiasis. That result agreed with studies of Franjola et al. (1995) and Ugbomoiko, (1997) and disagreed with Linardi et al. (2002) who found that the infection among males of $R$ norvegicus was significantly higher than that of females. He mentioned that the higher prevalence of infection among males could be attributed to behavioral and ecological factors. The higher prevalence could be attributed to ecological and behavioral factors. For examples male rats have larger home ranges as they show territorial behavior and in turn they are significantly more infected by $X$. cheopis than females. So their chances of being infected with trypanosomiasis increased (Linardi et al, 1985a).

There was no significant correlation between the densities of parasites and the number of white blood cells among $R$. rattus spp. However, there was an inverse statistically significant correlation between densities of parasites and the weights of the hosts. The rat which recorded highest parasite density $(60,000$ parasites/ microliter) was a female $R$. rattus captured indoor. Its white blood cells WBCs count was 20,000/ microliter and its weight was 141 grams while the rat with lowest density (260parasites/ microliter) was a female weighed 163 grams, captured indoor and its WBCs count was $6500 /$ microliter. The inverse correlation between the densities of the parasites and the weights of rats can be explained by the mul- tiplication profile of $T$. lewisi which starts exponential multiplication then the parasites number stabilizes and is cleared by immune response. The first exposure to T. lewisi provides the host long solid immunity (Albright et al, 1991). So in the present study most of infected rats which recorded the high densities of parasite were of low weights or young ages. A similar study on the relation between the rates of $T$. lewisi infection and total body length of $R$. norvegicus revealed that there was a gradual increase of infection rates with total body length in animals measuring $(60-170 \mathrm{~mm})$ and decreased thereafter. The highest rates were detected among young animals measuring (141-170 $\mathrm{mm}$ ) and immatures rats measuring (111$140 \mathrm{~mm}$ ). Significant differences were detected between the infection rates of length measuring (141-170 mm) and that of rats measuring $(171-200 \mathrm{~mm})$ also between the infection rate of the latter group and that of rats measuring (201-230 $\mathrm{mm}$ ) (Linardi et al, 2002).

Concerning the place of rodents capturing it was found that all positive rats were collected indoors (from houses) and all the rats captured from outdoors (farms) were negative for $T$. lewisi. The difference between infections with trypanosomiasis among rats inhabited the houses and that found in farms was highly significant. This result coincides with Pumhom who recorded a high prevalence of $T$. lewisi infection among rodents living near human settlement and in areas having high cover of built-up habitat (Pumhom et al, 2015). The results suggested strongly that the wild rodents act as reservoirs and serious source of atypical human trypanosomiasis caused by animal trypanosomes.

In the present study (November to March 2016) the estimated prevalence may not reflect the all over rate. Linardi (2002) recorded $T$. lewisi infection among $R$. norvigicus throughout the year except during February and March. Linardi (1985a,b) mentioned that the highest prevalences were recorded 
in the warm and rainy season especially in October and November.

Only two species of fleas were found on the collected rats, Xenopsylla cheopis and Leptopsylla segnis. The oriental fleas, $X$. cheopis, were found mainly on $R$. norvegicus where $57.5 \%$ of $R$. norvegicus were positive for $X$. cheopis while only one rat was positive for Leptopsylla segnis. On other hand the rat fleas, L. segnis, were found mainly on Rattus rattus spp where $39 \%$ of these rats were positive for $L$. segnis. In the spring seasons of 2009-2010 a survullence of domestic rodents and their fleas revealed that $X$. cheopis were the fleas of the highest frequent distribution on all domestic rodents (Mikhail et al, 2011).

The present work revealed a significant correlation between the presence of Leptopsylla segnis on the rats and the infection with $T$. lewisi however that correlation regarding Xenopsylla cheopis was not significant. Linardi $(1985 \mathrm{a}, \mathrm{b})$ revealed that the high level of infestation by $X$. cheopis coincide with high infection rate with $T$. lewisi .

\section{Recommendation}

Although few number of atypical human trypanosomiasis appeared recently all over the world, the high densities of the reservoir hosts (rodents) and flea vectors in our communities threaten people especially the classes of low immunity with infection by $T$. lewisi.So regular survey for rodents all over the country should be done. A plan for controlling fleas and rodents should be achieved. On research level molecular studies on the two species; Xenopsylla cheopis and Leptopsylla segnis should be done for detecting the vector which is responsible for transmission of $T$. lewisi.

\section{References}

Abdel-Aal, AA, Abou-Eisha, AM, 1997: The role of rats as reservoir of some internal parasites with possible public health implications in the Suez Canal area. Assiut Vet. Med. J. 37:17485.

Albright, JW, Albright, JF, 1991: Rodent trypanosomes: their conflict with the immune system of the host. Parasitol. Today 7:137-40.
Altman, D, 1992: Practical statistics for medical research 1st ed London: Champman and Hall. Chaisiri, K, Siribat, P, Ribas, A, Morand, S, 2015: Potentially zoonotic helminthiases of murid rodents from the Indo-Chinese peninsula: impact of habitat and the risk of human infection. Vector-Borne and Zoonotic Diseases (Larchmont, N.Y.) 15:73-85.

Davis, DE, 1948: The survival of wild brown rats on a Maryland farm. Ecol, 29:437-48.

De Carnieri, I, Castellino, S, 1964: Trypanosoma lewisi in un allevamento lombardo di ratti albini. Parassitol. 6:95-9.

Desquesnes, M, Kamyingkird, K, Yangtara, S, Milocco, C, Ravel, S, et al, 2011: Specific primers for PCR amplification of the ITS1 (ribosomal DNA) of Trypanosoma lewisi. Infect. Genet. Evol. 11:1361-7

Doke, PP, Kar, A, 2011: A fatal case of Trypanosoma lewisi in Maharashtra, India. Ann. Trop. Med. Publ. Hlth. 4:S91-5

Duncan, TMW, 1955: Multiple range and multiple F-tests. Biometric. 11:1-42.

Eyles, DE, 1952: Incidence of Trypanosoma lewisi and Hepatozoon muris in the Norway rat. J. Parasitol. 38:222-5.

Ferrante, A, 1985: Trypanolytic activity, agglutinins, and opsonins in sera from animals refractory to Trypanosoma lewisi. Infect. Immun. 49: 378-82

Franjola, R, Soto, G, Montefusco, A, 1995: Prevalencia de infección por protozoos en roedores sinantrópicos de la ciudad de Valdivia, Chile. Biol. Chil. Parasitol. 50:66-72.

Garcia, LS, 2001: Diagnostic Medical Parasitology. $4^{\text {th }}$ edition; ASM Press, Washington, DC.

Gutierrez, C, Desquesnes, M, Touratier, L, Büscher, P, 2010: Trypanosoma evansi: Recent outbreaks in Europe. Vet. Parasitol. 24, 174:26-9 Haridy, FM, El-Metwally, MT, Khalil, HH, Morsy, TA, 2011: Trypanosoma evansi in dromedary camel: with a case report of zoonosis in greater Cairo, Egypt. J. Egypt. Soc. Parasitol. 41, 1:65-76.

Herrera, L, Urdaneta-Morales, S, 1997: Synanthropic rodent reservoirs of Trypanosoma $(\mathrm{Sc}$ hizotrypanum) cruzi in the valley of Caracas, Venezuela. Rev. Inst. Med. Trop. São Paulo 39: 279 -82.

Hoare, CA, 1972: The trypanosomes of mammals: A zoological monograph. Oxford and Edinburgh: Blackwell Scientific Publications. 
Hoogstraal, H, 1956: The flea (Siphonaptera) of Egypt: Host-parasite relationship of rodents of the families Spalacidae, Muridae, Gliridae, Dipodidae and Hystricidae. J. Egypt. Pub. Hlth. Assoc. 39:1-35.

Jarvinen, JA, Dalmasso, AP, 1976: Complement in experimental Trypanosoma lewisi infection of rats. Infect. Immun. 14: 894-902.

Joshi, PP, Shegokar, V, Powar, S, Herder, S, Katti, R, 2005: Human Trypanosomiasis caused by Trypanosoma evansi in India: the first case report. Am. J. Trop. Med. Hyg. 73:491-5.

Laha, R, Hemaprasanth, H, Bhatta-Charya, D, 1997: Observations on prevalence of Trypanosoma lewisi infection in wild rats and a trial on its adaptation in unnatural host. J. Parasitol. Appl. Anim. Biol. 6:5-8.

Lehmann, E, 1975: Non-Parametric Statistical Method Based on Rank. $1^{\text {st }}$ ed. San Francisco, USA.

Linardi, PM, Botelho, JR, 2002: Prevalence of Trypanosoma lewisi in Rattus norvegicus from Belo Horizonte, State of Minas Gerais, Brazil. Mem. Inst. Oswaldo Cruz Rio De Jenero, 97, 3:411-4.

Linardi, PM, Botelho, JR, Cunha, HC, 1985: Ectoparasitos de roedores da região urbana de Belo Horizonte, MG. II- Oscilações dos índices de infestação em Rattus norvegicus norvegicus. Mem. Inst. Oswaldo Cruz 80:227-32.

Maia da Silva, F, Marcili A, Ortiz PA, Epiphanio S, Campaner M, et al, 2010: Phylogenetic, morphological and behavioral analyses support host switching of Trypanosoma (Herpetosoma) lewisi from domestic rats to primates. Infect Genet Evol 10: 522-9

Maraghi, S, Wallbanks, KR, Molyneux, DH, 1995: Oral transmission of trypanosomes of the subgenus Herpetosoma from small mammals. Parasitol, Res, 81:693-5

Mikhail, MW, Soliman MI, Morsy TA, 2011: The current status of fleas according to envi- ronmental changes in some governorates in Egypt J. Egypt. Soc. Parasitol. 41, 1:197- 210

Molyneux, A, David, H, 1969: The fine structure of the epimastigote forms of Trypanosoma lewisi in the rectum of flea, Nasopsyllus fasciatus. Parasitol. 59, 10:55-9.

Pumhom, P, Morand, S, Tran, A, Jittapalapong, S, Desquesnes, M, 2015: Trypanosoma from rodents as potential source of infection in human-shaped landscapes of South-East Asia PLoS Neglected Tropical Diseases are provided here courtesy of Public Library of Science doi:10.1016/j.vetpar.2014.12.027

Rassi, A Jr, Rassi, A, Marin-Nieto, JA, 2010: Chagas' disease. Lancet 375:1388-402

Rifaat, MN, Mohammed, AM, Shawarby, A A, Arafa, MS, 1969: Incidence and distribution of domestic and commensal rodents in U.A.R. J. Egypt. Pub. Hlth. Assoc. 44, 2: 127-46.

Sarataphan, N, Vongpakorn, M, Nuansrichay, B, Autarkool, N, Keowkarnkah, T, 2007: Diagno- sis of a Trypanosoma lewisi-like (Herpetosoma) infection in a sick infant from Thailand. J. Med. Microbiol. 56:1118-21

Truc, P, Buscher, P, Cuny, G, Gonzatti, MI, 2013: Atypical human infections by animal trypanosomes. PLos. Negl. Trop. Dis. 7, 9:e2256.

Truc, P, Jamonneau, V, N'Guessan, P, N'Dri, L, Diallo, PB, 1998: Trypanosoma brucei spp. And Trypanosoma congolense: mixed human infection in Côte d'Ivoire. Trans. R. Soc. Trop. Med. Hyg. 92:537-8.

Vanhamme, L, Paturiaux, F, Poelvoorde, P, Nolan, DP, Lins, L, 2003: Apolipoprotein L-I is the trypanosome lytic factor of human serum. Nature 422:83-7

Verma A, Manchanda S, Kumar N, Sharma A, Goel M, et al, 2011: Trypanosoma lewisi or T. lewisi-like infection in a 37 day old infant. Am. J. Trop. Med. Hyg. 85:221-4

WHO, 1970: Instruction resistance and vector control. Tech. Rep. Ser. No. 443, Geneva.

Table 1: Prevalence of infection with T. lewisi among rodents collected from Abu Alnomros Center. $\mathrm{X}^{2}=29.9, \mathrm{P}$

\begin{tabular}{|c|c|c|c|c|}
\hline \multirow{2}{*}{\multicolumn{2}{|c|}{ Rodent species }} & \multirow{2}{*}{\multicolumn{2}{|c|}{ Trypanosomiasis lewisi }} & \multirow{3}{*}{$\begin{array}{c}\text { Total } \\
44 \\
\end{array}$} \\
\hline & & & & \\
\hline & No. of rodents & $\begin{array}{c}\text { Negative } \\
44\end{array}$ & $\frac{\text { positive }}{0}$ & \\
\hline R. norvegicus & $\%$ & $100.0 \%$ & $0.0 \%$ & $100.0 \%$ \\
\hline \multirow{2}{*}{$R$. rattus } & No. of rodents & 20 & 21 & 41 \\
\hline & $\%$ & $48.8 \%$ & $51.2 \%$ & $100.0 \%$ \\
\hline \multirow{2}{*}{ Total } & No. of rodents & 64 & 21 & 85 \\
\hline & $\%$ & $75.3 \%$ & $24.7 \%$ & $100.0 \%$ \\
\hline
\end{tabular}


Table 2: Distribution of different rodents collected from Abu Alnomros Center, according to capturing place. $\mathrm{X}^{2}=27.6, \mathrm{P}<0.01$

\begin{tabular}{|c|c|c|c|c|}
\hline \multicolumn{2}{|c|}{ Species of rodents } & \multicolumn{2}{|c|}{ Place of rodent capturing } & \\
\cline { 3 - 5 } & No. of rodents & Indoors & Outdoors & \\
\hline \multirow{2}{*}{ R. norvegicus } & $\%$ & 22 & 22 & 44 \\
\cline { 2 - 5 } & No. of rodents & $50.0 \%$ & $50.0 \%$ & $100.0 \%$ \\
\hline \multirow{2}{*}{ R. rattus } & $\%$ & 41 & 0 & 41 \\
\cline { 2 - 5 } & No. of rodents & $100.0 \%$ & $0.0 \%$ & $100.0 \%$ \\
\cline { 2 - 5 } Total & $\%$ & 63 & 22 & 85 \\
\hline
\end{tabular}

Table 3: Rodents collected from Abu Alnomros Center, according to sex and infection with trypanosomiasis. $\mathrm{X}^{2}=0.63,0.04, \mathrm{P}>0.05$

\begin{tabular}{|c|c|c|c|c|c|}
\hline \multicolumn{3}{|c|}{ Rodent Species } & \multicolumn{2}{|c|}{ Trypanosoma lewis } & \multirow[t]{2}{*}{ Total } \\
\hline & & & & & \\
\hline \multirow{6}{*}{ R. norvegicus } & \multirow{2}{*}{ Male } & No. of rodents & 25 & 0 & 25 \\
\hline & & $\%$ & $100.0 \%$ & 0 & $100.0 \%$ \\
\hline & \multirow{2}{*}{ Female } & No. of rodents & 19 & 0 & 19 \\
\hline & & $\%$ & $100.0 \%$ & 0 & $100.0 \%$ \\
\hline & \multirow{2}{*}{ Total } & No. of rodents & 44 & 0 & 44 \\
\hline & & $\%$ & $100.0 \%$ & 0 & $100.0 \%$ \\
\hline \multirow{6}{*}{ R. rattus } & \multirow{2}{*}{ Male } & No. of rodents & 8 & 11 & 19 \\
\hline & & $\%$ & $42.1 \%$ & $57.9 \%$ & $100.0 \%$ \\
\hline & \multirow{2}{*}{ Female } & No. of rodents & 12 & 10 & 22 \\
\hline & & $\%$ & $54.5 \%$ & $45.5 \%$ & $100.0 \%$ \\
\hline & \multirow{2}{*}{ Total } & No. of rodents & 20 & 21 & 41 \\
\hline & & $\%$ & $48.8 \%$ & $51.2 \%$ & $100.0 \%$ \\
\hline \multirow{6}{*}{ Total } & \multirow{2}{*}{ Male } & No. of rodents & 33 & 11 & 44 \\
\hline & & $\%$ & $75.0 \%$ & $25.0 \%$ & $100.0 \%$ \\
\hline & \multirow{2}{*}{ Female } & No. of rodents & 31 & 10 & 41 \\
\hline & & $\%$ & $75.6 \%$ & $24.4 \%$ & $100.0 \%$ \\
\hline & \multirow{2}{*}{ Total } & No. of rodents & 64 & 21 & 85 \\
\hline & & $\%$ & $75.3 \%$ & $24.7 \%$ & $100.0 \%$ \\
\hline
\end{tabular}

Table 4: Distribution of different rodents collected from Abu Alnomros Center, according to flea spp. $\mathrm{X}^{2}=24.8, \mathrm{P}<0.01$

\begin{tabular}{|c|c|c|c|c|c|c|}
\hline \multirow{2}{*}{\multicolumn{2}{|c|}{ Rodent Species }} & \multicolumn{4}{|c|}{ Presence of Fleas } & \multirow{3}{*}{$\begin{array}{c}\text { Total } \\
44 \\
\end{array}$} \\
\hline & & \multirow{2}{*}{$\begin{array}{c}\text { Negative } \\
20\end{array}$} & \multirow{2}{*}{$\begin{array}{c}\text { Xenopsylla spp } \\
23\end{array}$} & \multirow{2}{*}{$\begin{array}{c}\text { Leptopsylla } s p p \\
0\end{array}$} & \multirow{2}{*}{$\begin{array}{c}\text { Both fleas } \\
1\end{array}$} & \\
\hline & No. of rodents & & & & & \\
\hline R. norvegicus & $\%$ & $45.5 \%$ & $52.3 \%$ & $0.0 \%$ & $2.3 \%$ & $100.0 \%$ \\
\hline \multirow{2}{*}{ R. rattus } & No. of rodents & 20 & 5 & 6 & 10 & 41 \\
\hline & $\%$ & $48.8 \%$ & $12.2 \%$ & $14.6 \%$ & $24.4 \%$ & $100.0 \%$ \\
\hline \multirow{2}{*}{ Total } & No. of rodents & 40 & 28 & 6 & 11 & 85 \\
\hline & $\%$ & $47.1 \%$ & $32.9 \%$ & $7.1 \%$ & $12.9 \%$ & $100.0 \%$ \\
\hline
\end{tabular}

Table 5: Correlation between Xenopsylla spp on rats and infection with T. lewisi.

\begin{tabular}{|c|c|c|c|}
\hline \multirow{4}{*}{ Xenopsylla spp } & Pearson Correlation & Xenopsylla spp & Trypanosomiasis \\
\cline { 2 - 4 } & Sig. (2-tailed) & 1 & .029 \\
\cline { 2 - 4 } & $\mathrm{N}$ & 85 & .793 \\
\hline \multirow{3}{*}{ Trypanosomiasis } & Pearson Correlation & .029 & 1 \\
\cline { 2 - 4 } & Sig. (2-tailed) & .793 & 85 \\
\cline { 2 - 4 } & $\mathrm{N}$ & 85 & 85 \\
\hline
\end{tabular}

Table 6: Correlation between Lepytopsylla spp on rats and infection with T. lewisi.

\begin{tabular}{|c|c|c|c|}
\hline & & Trypanosomiasis & Lepytopsylla spp \\
\hline \multirow{3}{*}{ Lepytopsylla spp } & Pearson Correlation & 1 & $427 * *$ \\
\hline & Sig. (2-tailed) & & .000 \\
\hline & $\mathrm{N}$ & 85 & 85 \\
\hline \multirow{3}{*}{ Trypanosomiasis } & Pearson Correlation & $.427^{* *}$ & 1 \\
\hline & Sig. (2-tailed) & .000 & .000 \\
\hline & $\mathrm{N}$ & 85 & 85 \\
\hline \multicolumn{4}{|c|}{ ** Spearman's rho correlation significant at 0.01 level (2-tailed). } \\
\hline \multirow{2}{*}{\multicolumn{4}{|c|}{\begin{tabular}{|c|c|} 
Table 7: Correlation between weights of rats and infection with $T . l$ & Weights
\end{tabular}}} \\
\hline & & Weights & Trypanosomiasis \\
\hline \multirow{3}{*}{ Weights } & Correlation Coefficient & 1.000 & $-.500-^{* * *}$ \\
\hline & Sig. (2-tailed) & & .000 \\
\hline & $\mathrm{N}$ & 85 & 85 \\
\hline \multirow{3}{*}{ Trypanosomiasis } & Correlation Coefficient & $-.500-^{* *}$ & 1.000 \\
\hline & Sig. (2-tailed) & .000 & \\
\hline & $\mathrm{N}$ & 85 & 85 \\
\hline \multicolumn{4}{|c|}{ **. Spearman's rho correlation significant at 0.01 level (2-tailed). } \\
\hline
\end{tabular}


Table 8: Rodents collected from Abu Alnomros Center, according to weights and trypanosomiasis infection $\mathrm{X}^{2}=23.6, \mathrm{P}<0.01$

\begin{tabular}{|c|c|c|c|c|c|c|c|}
\hline \multicolumn{2}{|c|}{ Weights of different species } & \multicolumn{2}{|c|}{ Negative for T. lewisi } & \multicolumn{2}{|c|}{ positive for T. lewisi } & \multicolumn{2}{|c|}{ Total } \\
\hline & & No. & $\%$ & No. & $\%$ & No. & $\%$ \\
\hline \multirow{6}{*}{$R$. norvegicus } & Less than 100 & 2 & $4.5 \%$ & & & 2 & $4.5 \%$ \\
\hline & 100 - less than 200 & 4 & $9.1 \%$ & & & 4 & $9.1 \%$ \\
\hline & 200 - less than 300 & 19 & $43.2 \%$ & & & 19 & $43.2 \%$ \\
\hline & 300 - less than 400 & 17 & $38.6 \%$ & & & 17 & $38.6 \%$ \\
\hline & 400 grams or more & 2 & $4.5 \%$ & & & 2 & $4.5 \%$ \\
\hline & Total & 44 & $100.0 \%$ & & & 44 & $100.0 \%$ \\
\hline \multirow{3}{*}{ R. rattus } & Less than 100 & 7 & $35.0 \%$ & 10 & $47.6 \%$ & 17 & $41.5 \%$ \\
\hline & 100 - less than 200 & 13 & $65.0 \%$ & 11 & $52.4 \%$ & 24 & $58.5 \%$ \\
\hline & Total & 20 & $100.0 \%$ & 21 & $100.0 \%$ & 41 & $100.0 \%$ \\
\hline \multirow{6}{*}{ Total } & Less than 100 & 9 & $14.1 \%$ & 10 & $47.6 \%$ & 19 & $22.4 \%$ \\
\hline & 100 - less than 200 & 17 & $26.6 \%$ & 11 & $52.4 \%$ & 28 & $32.9 \%$ \\
\hline & 200 - less than 300 & 19 & $29.7 \%$ & 0 & $0.0 \%$ & 19 & $22.4 \%$ \\
\hline & $300-$ less than 400 & 17 & $26.6 \%$ & 0 & $0.0 \%$ & 17 & $20.0 \%$ \\
\hline & 400 grams or more & 2 & $3.1 \%$ & 0 & $0.0 \%$ & 2 & $2.4 \%$ \\
\hline & Total & 64 & $100.0 \%$ & 21 & $100.0 \%$ & 85 & $100.0 \%$ \\
\hline
\end{tabular}

Table 9: White blood cells count/microliter \& trypanosomiasis among rats from Abu Alnomros Center, $\mathrm{X}^{2}=7.1, \mathrm{P}>0.05$

\begin{tabular}{|c|c|c|c|c|c|c|}
\hline \multicolumn{2}{|c|}{ WBCs count /microliter } & \multicolumn{4}{|c|}{ No. of parasites /microliter } & \multirow[t]{2}{*}{ Total } \\
\hline & & Negative & less than 1000 & $1000-<10,000$ & $10,000-60,000$ & \\
\hline \multirow{2}{*}{ Less than 5000} & No. & 15 & 2 & 9 & 0 & 26 \\
\hline & $\%$ & $57.7 \%$ & $7.7 \%$ & $34.6 \%$ & $0.0 \%$ & $100.0 \%$ \\
\hline \multirow{2}{*}{$\begin{array}{c}5000 \text { - less than } \\
10,000\end{array}$} & No. & 18 & 1 & 0 & 1 & 20 \\
\hline & $\%$ & $90.0 \%$ & $5.0 \%$ & $0.0 \%$ & $5.0 \%$ & $100.0 \%$ \\
\hline \multirow{2}{*}{$\begin{array}{c}\text { 10000-less than } \\
20000\end{array}$} & No. & 16 & 3 & 0 & 2 & 21 \\
\hline & $\%$ & $76.2 \%$ & $14.3 \%$ & $0.0 \%$ & $9.5 \%$ & $100.0 \%$ \\
\hline \multirow{2}{*}{ more than 20000} & No. & 16 & 0 & 0 & 2 & 18 \\
\hline & $\%$ & $88.9 \%$ & $0.0 \%$ & $0.0 \%$ & $11.1 \%$ & $100.0 \%$ \\
\hline \multirow{2}{*}{ Total } & No. & 65 & 6 & 9 & 5 & 85 \\
\hline & $\%$ & $76.5 \%$ & $7.1 \%$ & $10.6 \%$ & $5.9 \%$ & $100.0 \%$ \\
\hline
\end{tabular}

Table 10: Correlation between weights of rats and densities of T. lewisi.

\begin{tabular}{|c|c|c|c|}
\hline \multirow{2}{*}{$\begin{array}{c} \\
\text { Parasite/ } \\
\text { Microliter }\end{array}$} & Correlation Coefficient & Parasite/microliter & Weight \\
\cline { 2 - 4 } & Sig. (2-tailed) & 1.000 & $-.481-^{* *}$ \\
\cline { 2 - 4 } & $\mathrm{N}$ &. & .000 \\
\hline \multirow{3}{*}{ Weight } & Correlation Coefficient & $-.481-{ }^{* *}$ & 85 \\
\cline { 2 - 4 } & Sig. (2-tailed) & .000 & 1.000 \\
\cline { 2 - 4 } & $\mathrm{N}$ & 85 &. \\
\hline \multicolumn{2}{|c|}{} & $*$ Spearman's rho correlation significant at 0.01 level (2-tailed). \\
\hline
\end{tabular}

Table 11: Different rodents collected from Abu Alnomros Center, according place and fleas spp. $\mathrm{X}^{2}=2.8,4.6, \mathrm{P}>0.01$

\begin{tabular}{|c|c|c|c|c|c|c|c|c|c|c|c|}
\hline \multirow{2}{*}{\multicolumn{2}{|c|}{ Species }} & \multicolumn{8}{|c|}{ Negative } & \multirow{2}{*}{\multicolumn{2}{|c|}{ Xenopsylla spp }} \\
\hline & & \multicolumn{2}{|c|}{ Indoor } & \multicolumn{2}{|r|}{8} & \multicolumn{2}{|c|}{ Leptopsylla spp } & \multicolumn{2}{|c|}{ Both fleas } & & \\
\hline \multirow{3}{*}{$\begin{array}{c}\text { R. norvegi- } \\
\text { cus }\end{array}$} & Outdoors & 12 & $36.4 \%$ & 14 & $63.6 \%$ & 0 & $0.0 \%$ & 0 & $0.0 \%$ & 22 & $100.0 \%$ \\
\hline & Total & 20 & $54.5 \%$ & 9 & $40.9 \%$ & 0 & $0.0 \%$ & 1 & $4.5 \%$ & 22 & $100.0 \%$ \\
\hline & Indoor & 20 & $45.5 \%$ & 23 & $52.3 \%$ & 0 & $0.0 \%$ & 1 & $2.3 \%$ & 44 & $100.0 \%$ \\
\hline \multirow{2}{*}{ R. rattus } & Total & 20 & $48.8 \%$ & 5 & $12.2 \%$ & 6 & $14.6 \%$ & 10 & $24.4 \%$ & 41 & $100.0 \%$ \\
\hline & Indoor & 28 & $48.8 \%$ & 5 & $12.2 \%$ & 6 & $14.6 \%$ & 10 & $24.4 \%$ & 41 & $100.0 \%$ \\
\hline \multirow{2}{*}{ Total } & Outdoors & 12 & $44.4 \%$ & 19 & $30.2 \%$ & 6 & $9.5 \%$ & 10 & $15.9 \%$ & 63 & $100.0 \%$ \\
\hline & 40 & $47.1 \%$ & $54.5 \%$ & 9 & $40.9 \%$ & 0 & $0.0 \%$ & 1 & $4.5 \%$ & 22 & $100.0 \%$ \\
\hline \multicolumn{2}{|c|}{ Total } & & & & & & & & & & \\
\hline
\end{tabular}

Fig Explanation of figures

Fig 1: T. lewisi among different rodents collected from Abu Alnomros Center

Fig. 2: Rodent species collected from Abu Alnomros Center, place of rodent capturing.

Figs. 3, 4: Rodent species collected from Abu Alnomros Center, sex and trypanosomiasis infection.

Fig. 5: Rodent species collected from Abu Alnomros Center, Alnomros Center, fleas spp.

Fig. 6: White blood cells count / microliter and trypanosomiasis among rats in Abu Alnomros Center.

Fig. 7: White blood cells count / microliter and densities of parasites/microliter among rats in Abu Alnomros Center.

Fig. 8: Rodent species collected from Abu Alnomros Center, weights and trypanosomiasis infection.

Figs. 9, 10: Rodent species collected from Abu Alnomros Center, place of capturing and fleas spp. 


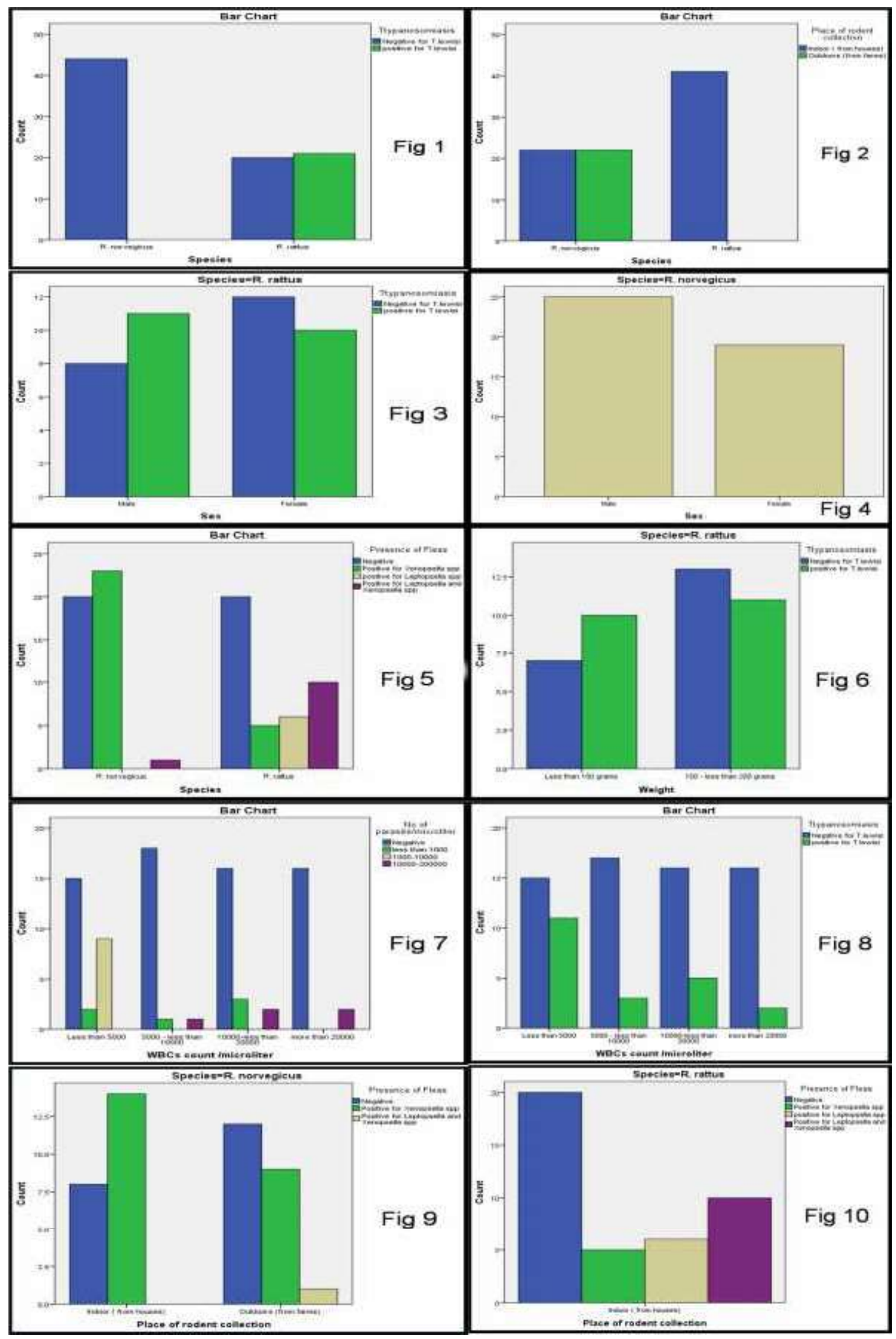




\section{Explanation of photos}

Photo 1: Rattus norvegicus

Photo 2: Rattus rattus frugivorus

Photo 3: Rattus rattus alexandrinus

Photo 4: A closed jar containing cotton with diethyl ether for general anesthetic

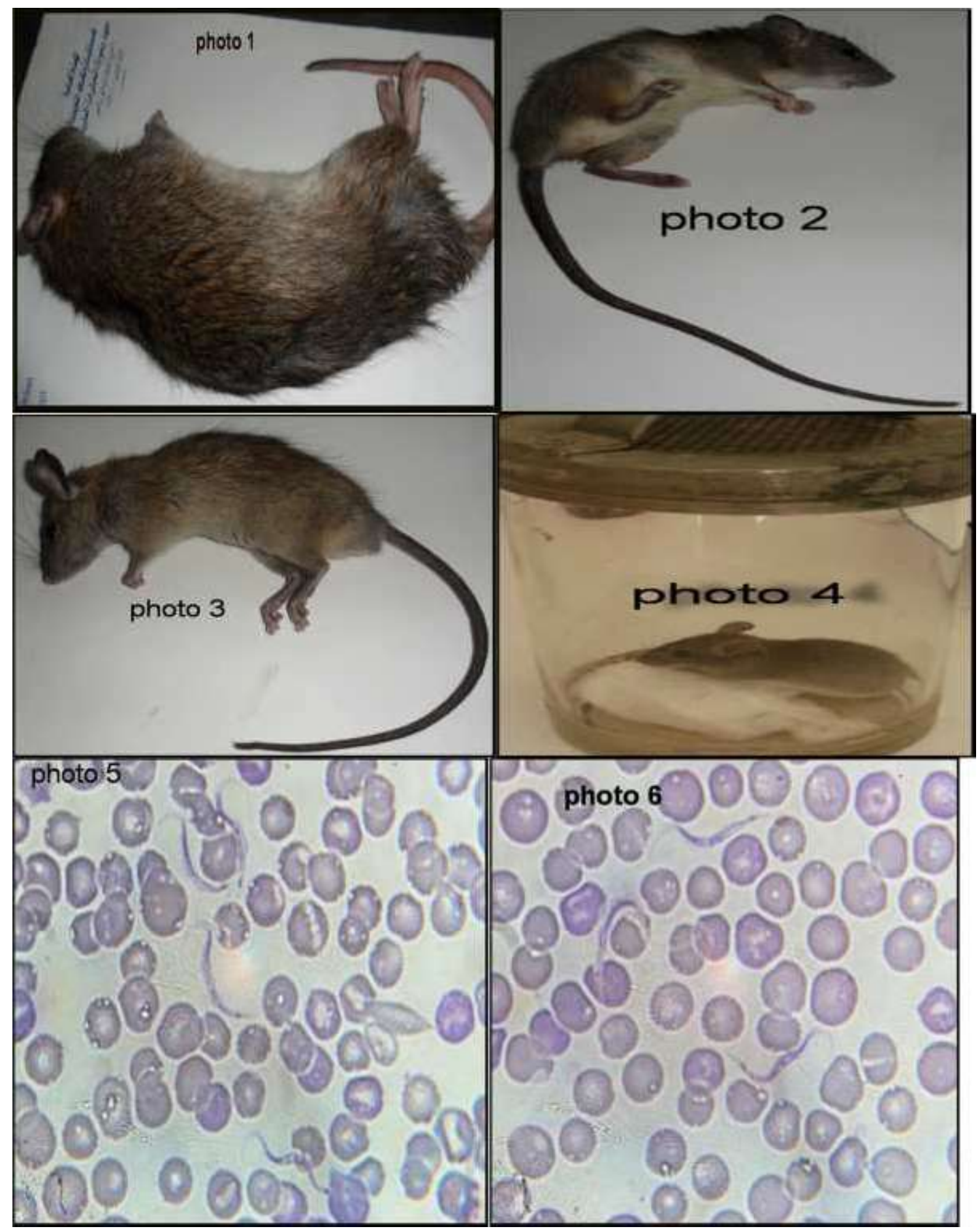

